\title{
Mechanical and Permeability Characteristics of Latex-Modified Fiber-Reinforced Roller-Compacted Rapid-Hardening-Cement Concrete for Pavement Repair
}

\author{
Seung-Kee Lee ${ }^{1}$, Myong-Jin Jeon ${ }^{1}$, Sang-Sun Cha ${ }^{2}$ and Chan-Gi Park ${ }^{2, *}$ \\ 1 Department of Bio-Industry Mechanical Engineering, Kongju National University, Yesan 143-701, Korea; \\ leesk@kongju.ac.kr (S.-K.L.); myonggene@kongju.ac.kr (M.-J.J.) \\ 2 Department of Rural Construction Engineering, Kongju National University, Yesan 143-701, Korea; \\ chass@kongju.ac.kr \\ * Correspondence: cgpark@kongju.ac.kr; Tel.: +82-41-330-1266; Fax: +82-41-330-1269
}

Academic Editor: Stefano Invernizzi

Received: 9 May 2017; Accepted: 29 June 2017; Published: 5 July 2017

\begin{abstract}
This study evaluated the effects of reinforcement fibers on the mechanical characteristics, chloride ion penetration properties and abrasion resistance of roller-compacted latex-modified fiber-reinforced rapid-hardening-cement concrete (RCLMFRRHCC) for use in the emergency repair of concrete pavements. The reinforcement fibers tested included macro synthetic fibers (a structural fiber) as well as PVA (polyvinyl alcohol) and natural Jute fibers (non-structural fibers). In the experiment, compressive strength, flexural strength, splitting tensile strength, chloride ion penetrating properties, abrasion resistance tests and impact resistance tests were performed. Test results were compared with traffic open standards of concrete for concrete pavement emergency repair. RCLMFRRHCC satisfied all traffic open standards for concrete emergency repair. Mixes with reinforcement fibers showed superior results to the mix without, in terms of compressive strength, flexural strength, splitting tensile strength, chloride ion penetration resistance, abrasion resistance and impact resistance. With regard to the reinforcement fibers, the compressive strength, flexural strength, splitting tensile strength, and impact resistance of the mix with macro synthetic fiber showed improved results as a structural fiber compared to mixes containing natural jute and PVA fibers, namely the non-structural fibers. However, using the reinforcement fiber type had little effect on chloride ion penetration resistance or abrasion resistance. Thus, the addition of reinforcement fibers was effective in improving the performance of RCLMFRRHCC. The use of macro synthetic fibers improved the mechanical characteristics of concrete.
\end{abstract}

Keywords: chloride ion penetration; mechanical properties; jute fiber; latex; macro synthetic fiber; PVA fiber; pavement repair; rapid hardening cement

\section{Introduction}

New methods and materials for repairing old or damaged pavement are necessary given the increasing demand placed on roadway infrastructure [1-6]. Road repairs require rapid reopening after a short-term period of blocking traffic to minimize traffic congestion [7-11]. Typically, rapid-hardening cement concrete is used for this purpose [12,13]. During the hardening process, hydration heat is generated when the compounds in the cement form chemical bonds with water [1-3,6,12]. Thus, hydration is required for hardening/curing [1-3,6,12]. Early strength is achieved by enhancing the movement of heat and moisture inside the concrete pavement structure for rapid hardening [6,12]. 
However, under the conditions of the actual site, the movement of heat and moisture is restricted, internally and externally, causing tensile stress in the concrete and ultimately, fine crack formation $[6,12]$.

Fine cracks allow water to penetrate the concrete pavement, leading to defect formation, loss of original function and other problems requiring near-term future repairs $[4,6,7]$. Latex is added to rapid-hardening cement to improve its workability and durability $[13,14]$. The viscosity of latex helps to prevent separation of materials. Thus, it increases the flexural strength and tensile force/formability of concrete [12-14]. This occurs due to the surfactant interactions with the latex components $[5,10,11]$. The formation of a latex film improves the bond strength and mechanical properties of the concrete, while increasing the concrete's resistance to water permeability $[5,10,11]$. Other advantages of adding latex to concrete include improved viscosity, water tightness, freezing and thawing resistance in addition to anti-abrasion and anti-chemical resistance [10-14]. However, despite the excellent workability and durability of latex-modified rapid-set cement concrete, it still has the same problems associated with rapid-set cement $[10-12,15]$. The addition of latex to concrete tends to delay the onset of the targeted initial strength $[12,15]$. Therefore, a large amount of rapid set cement should be used. In particular, the use of a large amount of rapid set cement for securing initial strength produces hydration heat, resulting in crack formation due to shrinkage/contraction, temperature variation and restraints inside the concrete $[6,12,13,15]$. The occurrence of these cracks reduces the time between subsequent re-pavement maintenance due to a deterioration in pavement durability with water permeability [10-13]. Thus, with massive use of ultra-rapid hardening cement, it is important to find the means to minimize or prevent hydration-heat crack formation to improve the durability of concrete and in turn, reduce the time and cost involved by deferring the requirement for re-pavement $[12,13,15]$. In this research, crack formation was controlled by the use of reinforced fibers.

The addition of reinforcing fibers minimized concrete crack formation by dispersing the fibers in random directions throughout the concrete [16-23]. Additionally, the dispersion of the reinforcing fibers improved the brittle and ductile properties of the concrete by inhibiting crack formation and growth [17-20]. Fiber-reinforced concrete (FRC) is concrete that contains or is reinforced with dispersed, randomly-oriented and unconnected fibers [16]. Concrete is indigenously brittle, but if reinforced with fibers within its structure, such brittleness is rectified and its ductile property is improved due to the suppression of crack growth by the reinforced fibers [17-21].

Furthermore, in the method of suppressing the occurrence of cracks, the water-cement ratio is lowered to reduce the amount of water used $[22,23]$. The roller compaction concrete is applied in this study in terms of construction. Roller compaction concrete can be installed at a low water-cement ratio and can suppress shrinkage cracks caused by water evaporation. It also has the advantage of excellent construction ability [24]. Roller-compacted concrete (RCC) has low mobility. RCC refers to concrete for which compacting is performed with external vibrators, such as vibration rollers, because it does not have the consistency required of general concrete [24-27]. Roller-compacted concrete pavements (RCCPs) facilitate rapid, consecutive construction and wide construction boundaries. Thus, RCC techniques have higher economic feasibility than general concrete engineering methods [24-27]. Compared with general concrete pavements, RCCPs are stronger as they have lower water-to-cement ratios, with minimal contraction crack formation from moisture evaporation. Thus, in the long term, RCC materials provide the advantage of increased durability [24-27].

Currently, the latex-modified rapid-hardening-cement concrete used in repairs contains $15 \%$ latex (15\% of the cement weight) $[6,12,15]$. The use of $15 \%$ latex is difficult to apply to roller-compacted concrete with requirements of low slump. Therefore, the use of latex should be reduced. In this regard, the use of less latex would be desirable. However, given the advantages of latex, this would require new methods and materials to achieve the desired performance from the repair concrete. The addition of reinforcement fibers distributes the fibers in random directions inside the concrete so that the concrete's crack control ability may be improved [16-18]. Fiber-reinforced concrete also enhances the brittle properties of the concrete and improves ductile performance, preventing crack generation and growth [19-23]. The degree of the increase in crack control capacity attributable 
to fiber reinforcement of concrete is determined by the bonding mechanism between the fibers and the concrete, including fiber bridging, fiber de-bonding, fiber pullout and fiber fracture when cracks occur [16-23]. The bond characteristics are influenced by a variety of factors, such as the morphological shape and length of the reinforcing fiber, the surface property, the interface between the concrete and the reinforcing fiber in addition to the strength of the concrete [22,23]. In general, there are two approaches to improve the bonding characteristics of the fiber $[16,17,22,23]$. The first is mechanical improvement using fibers having crimped, hooked and twisted shapes $[16,22,23]$. The second is chemical treatment to improve the hydrophilicity of the fiber surface and thereby, improve compatibility with the concrete [16-23]. As reinforcement fibers, mixed polyolefin macro synthetic fibers, natural Jute fibers and PVA (polyvinyl alcohol) fibers were evaluated in terms of mechanical characteristics, chloride ion penetration properties and durability. Jute and PVA fibers are hydrophilic fibers and have excellent bonding strength with concrete [16]. Furthermore, the macro fibers are hydrophobic fibers, but the surface shape is treated as a crimp type in order to improve the bonding characteristics [22,23]. Therefore, PVA, jute and macro synthetic fibers are excellent in terms of bonding strength with concrete, which increases the control effect of cracks occurring in concrete. Therefore, they are effective in improving durability, including permeability of concrete. Such an effect can sufficiently solve the reduction in permeability and durability due to a reduction in latex usage. The study evaluated the performance of roller-compacted latex-modified fiber-reinforced rapid-hardening-cement concrete (RCLMFRRHCC) for repairing road pavement. When the amount of latex used was reduced from $15 \%$ to $5 \%$, the effectiveness of the types of reinforcing fibers to maintain or improve the target performance while securing a slump capable of roller compaction was evaluated. In addition, the effect of fiber type on abrasion and impact resistance were evaluated.

\section{Materials and Mix Proportions}

\subsection{Materials}

This study used the rapid-hardening cement by Jungang Polytech, Keyongnam, Korea. The physical and chemical characteristics of the rapid-hardening cement are shown in Tables 1 and 2. Crushed aggregates of maximum dimensions of $13 \mathrm{~mm}$ were used as the coarse aggregate, while river sand of density $2.60 \mathrm{~g} / \mathrm{mm}^{3}$ was used as the fine aggregate. The physical characteristics of the aggregates are listed in Table 3. Stylene butadiene latex (SB latex) from Jungang Polytech was used, with its characteristics given in Table 4. A macro synthetic fiber (a structural fiber) as well as a PVA fiber and natural jute fiber (non-structural fibers) were used as reinforcement fibers, which were produced by Nycon Materials, Co. Ltd., Seoul, Korea. The characteristics of the reinforcement fibers are listed in Table 5 and the shapes of the fibers are shown in Figure 1.

Table 1. Chemical and mineral compositions of rapid-hardening cement.

\begin{tabular}{cccccccccccc}
\hline \multicolumn{1}{c}{ Chemical Compositions (\%) } & \multicolumn{4}{c}{ Mineral Compositions (\%) } \\
\hline $\mathrm{SiO}_{2}$ & $\mathrm{Al}_{2} \mathrm{O}_{3}$ & $\mathrm{Fe}_{2} \mathrm{O}_{3}$ & $\mathrm{CaO}$ & $\mathrm{MgO}$ & $\mathrm{K}_{2} \mathrm{O}$ & $\mathrm{SO}_{3}$ & $\mathrm{C}_{3} \mathrm{~S}$ & $\mathrm{C}_{2} \mathrm{~S}$ & $\mathrm{C}_{4} \mathrm{~A}_{3} \mathrm{~S}$ & $\mathrm{C}_{3} \mathrm{~A}$ & $\mathrm{C}_{4} \mathrm{AF}$ \\
$13.0 \pm 3.0$ & $17.5 \pm 3.0$ & $<3.0$ & $50.0 \pm 3.0$ & $<2.5$ & 0.21 & $14 \pm 3$ & 16.0 & 16.0 & 30.0 & 3.0 & 6.0 \\
\hline
\end{tabular}

Table 2. Physical properties of rapid-hardening cement.

\begin{tabular}{ccccccc}
\hline \multirow{2}{*}{$\begin{array}{c}\text { Density } \\
\left(\mathrm{g} / \mathrm{mm}^{\mathbf{3}}\right)\end{array}$} & $\begin{array}{c}\text { Blaine Fineness } \\
\left(\mathrm{cm}^{\mathbf{2}} / \mathrm{g}\right)\end{array}$ & \multicolumn{2}{c}{ Setting Time $(\mathrm{min})$} & \multicolumn{3}{c}{ Compressive Strength (MPa) } \\
\cline { 3 - 7 } & & Initial & Final & $\mathbf{3 ~ \mathbf { ~ }}$ & $\mathbf{1}$ days & $\mathbf{2 8}$ days \\
\hline 2.87 & 5302 & 14 & 21 & 28.2 & 35.8 & 52.7 \\
\hline
\end{tabular}

Table 3. Physical properties of coarse aggregate.

\begin{tabular}{cccc}
\hline Properties & Density $\left(\mathrm{g} / \mathrm{mm}^{3}\right)$ & Absorption (\%) & F.M. \\
\hline Value & 2.61 & 0.35 & 6.92 \\
\hline
\end{tabular}


Table 4. Properties of styrene butadiene latex.

\begin{tabular}{|c|c|c|c|c|c|c|c|}
\hline $\begin{array}{c}\text { Solids } \\
\text { Content (\%) }\end{array}$ & $\begin{array}{c}\text { Styrene } \\
\text { Content }(\%)\end{array}$ & $\begin{array}{c}\text { Butadiene } \\
\text { Content (\%) }\end{array}$ & $\mathrm{pH}$ & $\begin{array}{l}\text { Specific } \\
\text { Gravity }\end{array}$ & $\begin{array}{c}\begin{array}{c}\text { Surface Tension } \\
\text { (dyne/cm) }\end{array} \\
\end{array}$ & $\begin{array}{l}\text { Particle } \\
\text { Size (Å) }\end{array}$ & $\begin{array}{l}\text { Viscosity } \\
\text { (cps) }\end{array}$ \\
\hline 30 & $34 \pm 1.5$ & $66 \pm 1.5$ & 11.0 & 1.02 & 30.57 & 1700 & 42 \\
\hline
\end{tabular}

Table 5. Properties of fibers.

\begin{tabular}{cccc}
\hline Properties & Synthetic Macro Fiber & PVA Fiber & Natural Jute Fiber \\
\hline Elastic modulus $(\mathrm{GPa})$ & 10 & 45 & 61 \\
Density $\left(\mathrm{g} / \mathrm{mm}^{3}\right)$ & 0.91 & 1.26 & 1.26 \\
Fiber length $(\mathrm{mm})$ & 30 & 6 & 3 \\
Fiber diameter $(\mathrm{mm})$ & 1 & 0.015 & 0.015 \\
Tensile strength $(\mathrm{MPa})$ & 550 & 1600 & 510 \\
\hline
\end{tabular}

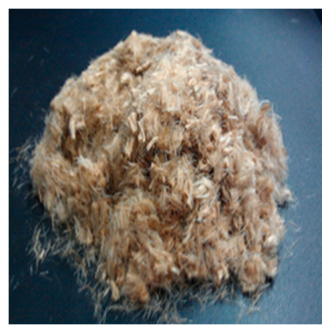

(a)

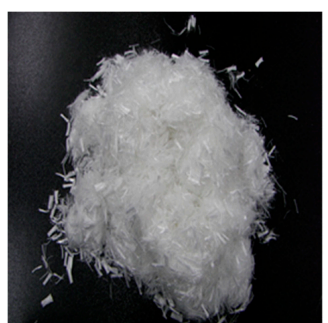

(b)

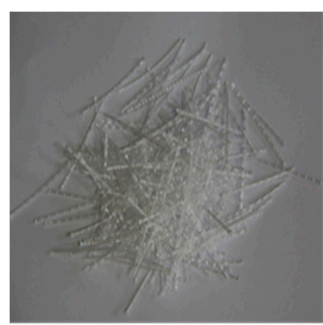

(c)

Figure 1. Geometry of fibers. (a) Jute fiber; (b) PVA fiber; (c) Macro synthetic fiber.

\subsection{Mix Proportions}

In concrete pavement repairs using rapid-hardening cement, a minimum of $4 \mathrm{~h}$ of curing time is specified as the traffic open time by the American Association of State Highway and Transportation Officials (AASHTO), the road traffic administration of each state in the United States, and the Korea Expressway Corporation [28,29]. The traffic open standards are as follows: a compressive strength $\geq 21 \mathrm{MPa}$ and a flexural strength $\geq 3.5 \mathrm{MPa}$. Furthermore, the splitting tensile strength was set at $3.2 \mathrm{MPa}$ or more in this study. After 28 days of curing, the compressive strength should be $\geq 35 \mathrm{MPa}$ and the flexural strength $\geq 4.5 \mathrm{MPa}$, with a splitting tensile strength $\geq 4.2 \mathrm{MPa}$. As such, the guidelines given were set at the mix goals of our study, as the intention was to apply the rapid-hardening cement to concrete pavement repair. Durability measures were based on water and chloride ion penetration test results, which have the biggest influence on a concrete pavement's usage life degradation. The chloride ion penetration amount was assessed according to the ASTM C 1202 test method [30], based on the standards of the Korea Expressway Corporation. The goal was $\leq 2000$ Coulombs after 28 days of curing [29]. In this study, to ensure initial durability, the goal of chloride ion penetration at $4 \mathrm{~h}$ of curing was set at $4000 \mathrm{C}$ or less. The target slump value was aimed at less than $40 \mathrm{~mm}$, which is applied to concrete pavement mixture of Korea Highway Corporation, Keyongnam, Korea [31]. To achieve these goals, the mix had a water-to-cement $(\mathrm{W} / \mathrm{C})$ ratio of 0.28 . Latex was added in at $5 \%$ of the cement weight. For the reinforcement fiber, $0.10 \%$ each of the synthetic macro fiber, natural jute fiber and PVA fiber were mixed. The mix ratios used are shown in Table 6.

The cement, fine aggregate and coarse aggregate were added to the mixture. After this, the mixture was subjected to a mixing for $1 \mathrm{~min}$ and $30 \mathrm{~s}$, followed by addition of water, which was mixed for $30 \mathrm{~s}$. Following this, the fiber was placed and mixing was performed, before the latex was finally added. The addition of latex can increase the slump initially and increase the fiber dispersion effect. However, loss of slump occurs when fibers are dispersed. In order to improve the dispersibility of the fibers, mixing was conducted for $1 \mathrm{~min}$ and $30 \mathrm{~s}$ after the fiber was added. Further, after the addition of the latex, additional mixing was performed for about $1 \mathrm{~min}$ and $30 \mathrm{~s}$. 
Table 6. Mix proportions of roller-compacted latex-modified fiber-reinforced rapid-hardening-cement concrete (RCLMFRRHCC) for pavement repair.

\begin{tabular}{|c|c|c|c|c|c|c|c|c|}
\hline \multirow{2}{*}{ Type of Mix } & \multirow{2}{*}{ W/C (\%) } & \multirow{2}{*}{ S/A (\%) } & \multicolumn{6}{|c|}{ Unit Weight $\left(\mathrm{kg} / \mathrm{m}^{3}\right)$} \\
\hline & & & Water & Cement & Sand & Gravel & Latex (Solid) & Fiber \\
\hline Plain & & & & & & & & - \\
\hline Structural synthetic & 28 & 55 & 112 & 400 & 1015 & 831 & 20 & 0.91 \\
\hline PVA (polyvinyl alcohol) & & & & & & & & $\begin{array}{l}1.20 \\
1.26\end{array}$ \\
\hline
\end{tabular}

\subsection{Manufacturing of Test Specimens}

The study used a pressure vibration compaction machine to mimic roller compaction in a laboratory to produce test specimens. It would be a more practical experiment to construct the experimental specimen by casting the pavement concrete using the roller compaction method and collecting the core. However, it is practically difficult to produce a specimen by using the roller compaction method in the laboratory. Therefore, specimens were manufactured using mimic roller compaction methods, which are easy to produce specimens using existing research [15]. First, one-third of the mixed latex-modified fiber-reinforced rapid-hardening-cement concrete was poured into the test mold and vibration was conducted for $30 \mathrm{~s}$ using a vibration-compacting machine to apply pressure. Similarly, for the second test, one-third of the concrete was put in the test mold and pressure vibration-compacting was performed for $30 \mathrm{~s}$. Finally, the last third was placed in the test mold. After pressure vibration compaction, the surface was finished. Figure 2 shows photographs of the pressure vibration-compacting machine used and manufacturing of test specimens.

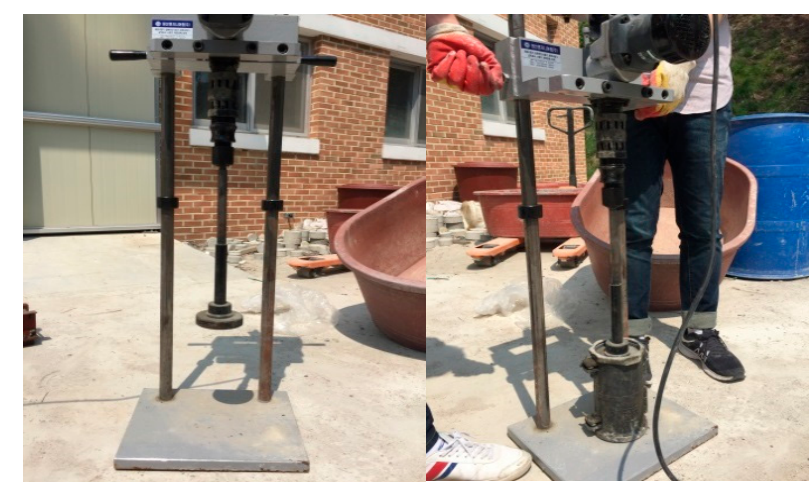

(a)

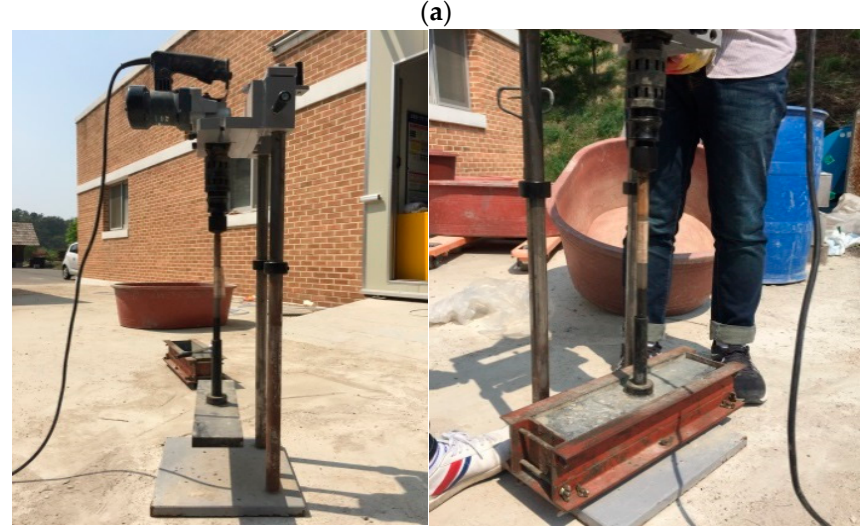

(b)

Figure 2. Manufacturing of test specimens. (a) Manufacturing of compressive strength specimens; (b) Manufacturing of flexural strength specimens. 


\section{Test Methods}

\subsection{Slump Tests}

Slump tests were performed in accordance with the ASTM C 143 standard [32]. The test was performed four times for each variable.

\subsection{Compressive Strength Tests}

Compressive strength tests were performed in accordance with the ASTM C 39 standard [33]. Tests were performed after $4 \mathrm{~h}$ and 28 days of curing. Each variable was investigated using six specimens.

\subsection{Splitting Tensile Test}

Splitting tensile tests were conducted in accordance with the ASTM C 496 standard [34]. Tests were carried out after curing periods of 28 days. Specimens $(100 \times 200 \mathrm{~mm})$ were cured in water at $23 \pm 2{ }^{\circ} \mathrm{C}$. Each variable was investigated using six specimens.

\subsection{Flexural Tests}

Flexural tests were conducted in accordance with the ASTM C 78 standard [35]. Each test was performed after $4 \mathrm{~h}$ and 28 days of curing. Each variable was investigated using six specimens.

\subsection{Chloride Ion Penetration Tests}

Chloride ion penetration tests were conducted in accordance with the ASTM C 1202-94 standard [30]. Specimens, which were $150 \times 50 \mathrm{~mm}$ in size, were tested after 28 days of curing. Each variable was investigated using six specimens. The test apparatus for the chloride ion penetration test is shown in Figure 3.
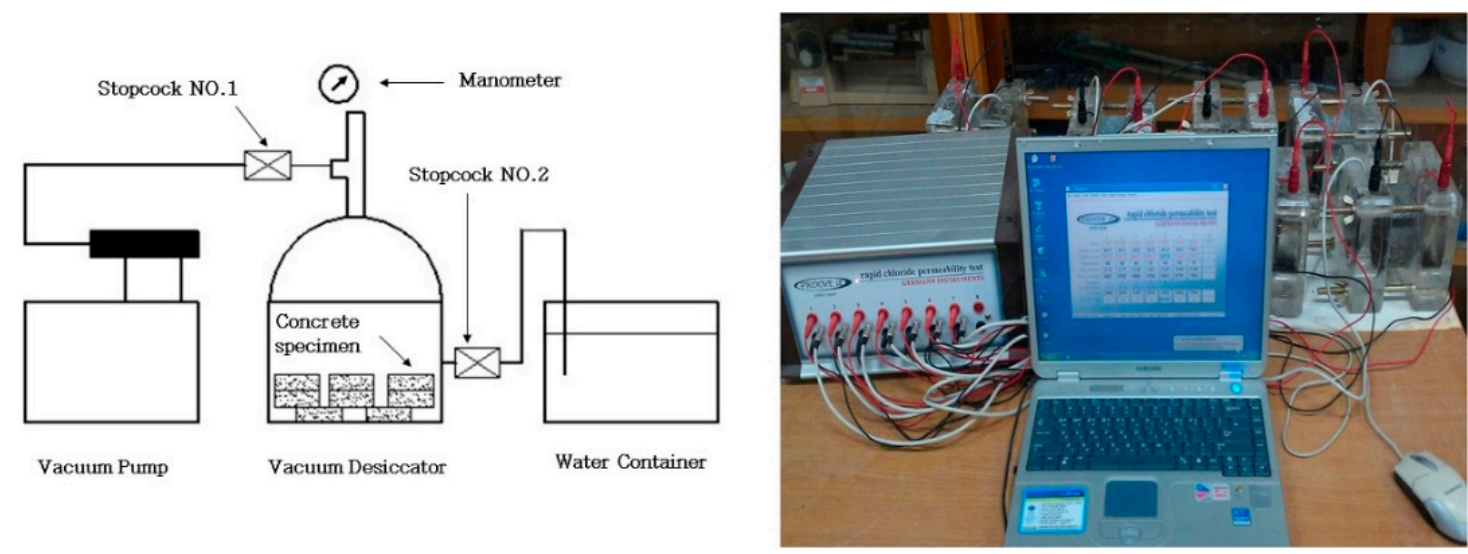

Figure 3. Chloride ion penetration test set-up.

\subsection{Abrasion Tests}

Abrasion tests were conducted in accordance with the ASTM C 944 standard [36]. Specimens, which were $150 \mathrm{~mm} \times 60 \mathrm{~mm}$ in size, were tested after 7 days of curing. Each variable was investigated using six specimens. The test apparatus for the abrasion test is shown in Figure 4. 


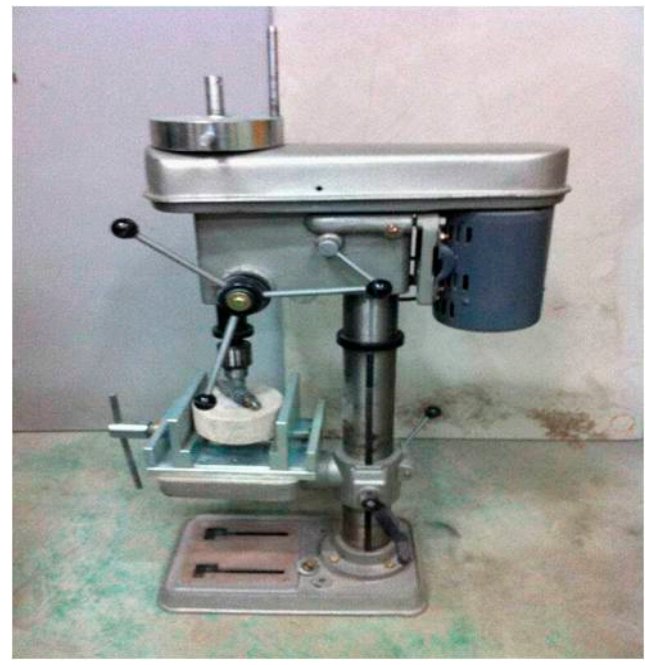

Figure 4. Abrasion test set-up.

\subsection{Impact Tests}

Impact tests were conducted in accordance with the specifications of the ACI Committee 544 [37]. Specimens, which were $150 \times 60 \mathrm{~mm}$ in size, were cured in water at $23 \pm 2{ }^{\circ} \mathrm{C}$. Each test was performed after 7 days of curing. Each variable was investigated using six specimens. The test apparatus for the impact test is shown in Figure 5.

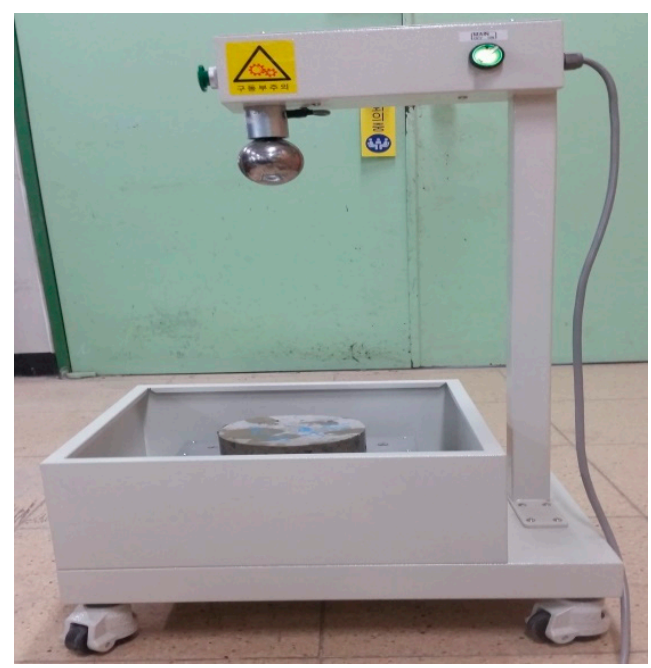

Figure 5. Impact test set-up.

\section{Results and Discussion}

\subsection{Slump Value}

The slump test result of RCLMFRRHCC, according to the type of reinforcing fiber, is shown in Figure 6 . The addition of reinforcing fibers results in a decrease in the slump value of RCLMFRRHCC. When the fiber was not added, a slump value of about $84 \mathrm{~mm}$ was shown. In comparison, when the fiber was added, the slump of $40 \mathrm{~mm}$ or less was obtained. When fibers are added to concrete, the slump decreases due to the bridging effect of the fibers [10,14], which was seen in this present study. Furthermore, since the hydrophilic fiber absorbs the mixing, there is a reduction in the water of the 
slump $[10,11,14]$. In this study, jute fibers and PVA fibers were applied as hydrophilic fibers. Therefore, slump loss was significantly higher than that of macro synthetic fibers, which has a hydrophobic surface. In this study, the target slump was determined to be $40 \mathrm{~mm}$ or less in order to apply the roller compaction method. As a result of the slump test, the mixture containing fibers satisfied the target slump, but did not satisfy the target slump value when no fiber was added. Therefore, in order to apply roller compaction method, it is necessary to add reinforcing fibers according to the slump test. However, the test specimens for evaluating the strength, permeability and durability of plain mixture without the addition of fibers were also prepared using a mimic roller compression method.

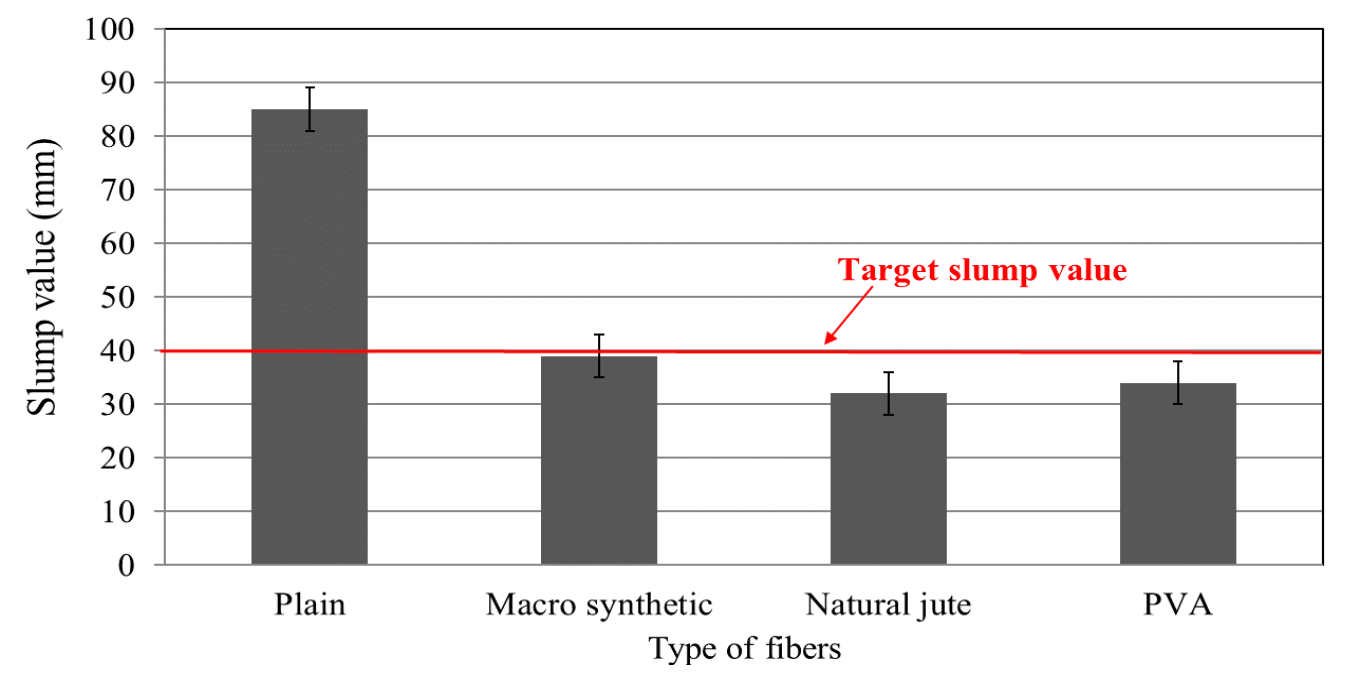

Figure 6. Slump test results.

\subsection{Compressive Strength}

Figure 7 shows the compressive strength test results according to the type of reinforcement fiber used in RCLMFRRHCC for emergency concrete pavement repair. Regardless of the reinforcement fiber, all mixes satisfied the goal of a 4-h strength of $\geq 21 \mathrm{MPa}$. Furthermore, after a period of 28 curing days, they all satisfied the strength requirements of $\geq 35 \mathrm{MPa}$. Compared with the mix that contained no reinforcement fibers, the compressive strength of the mixes using reinforcement fibers was slightly higher. The compressive strength of the mix using macro synthetic fibers was the highest. It showed a similar compressive strength to the mixes with natural jute fibers and PVA fibers. Generally, when latex is added, it has the effect of delaying the hardening time of the concrete. Thus, this delays the time to achieve the desired compressive strength $[5,11,12,15]$. To address this problem, we reduced the latex amount to $5 \%$ of the cement weight from $15 \%$, which is used generally in pavement repair $[6,12,13,15]$. Furthermore, during compaction, pressure vibration compaction was used to mimic roller compaction; it had the effect of tightening the concrete structure [24-27]. Thus, all samples satisfied the 4-h curing compressive strength of $21 \mathrm{MPa}$ and 28-day curing compressive strength of $35 \mathrm{MPa}$, which are standards for emergency repair concrete. When reinforcement fibers were added, it effectively suppressed crack generation by hydration heat and thus, increased the compressive strength slightly $[6,11,12]$. However, the increase in compressive strength was not significant. The reason for this is that the addition of reinforcing fibers is effective in increasing tensile and flexural strengths rather than compressive strengths. However, a slight increase in strength can be expected in terms of crack controls [16]. 
Fiber reinforcing materials can be classified into structural fibers to improve structural performance, such as strength and non-structural fibers to be used for crack control and durability improvement [16]. Structural fibers include steel fibers and structural synthetic fibers [22,23]. Nonstructural fibers include polypropylene fibers, jute fibers, and PVA fibers. In this study, macro synthetic fibers, which can replace steel fibers as structural fibers, was applied, while jute fibers and PVA fibers were applied as nonstructural fibers [16]. The mix using macro synthetic fibers had a higher compressive strength than the mixes using other reinforcement fibers. This is because the macro synthetic fiber is a structural fiber that can replace steel fiber and improve the mechanical performance of the concrete, which is reflected in the structural performance $[16,22,23]$. Thus, the mix with the macro synthetic fiber showed a slightly higher compressive strength than jute fiber and PVA fiber mixes, the main purpose of which was crack control, rather than structural performance.

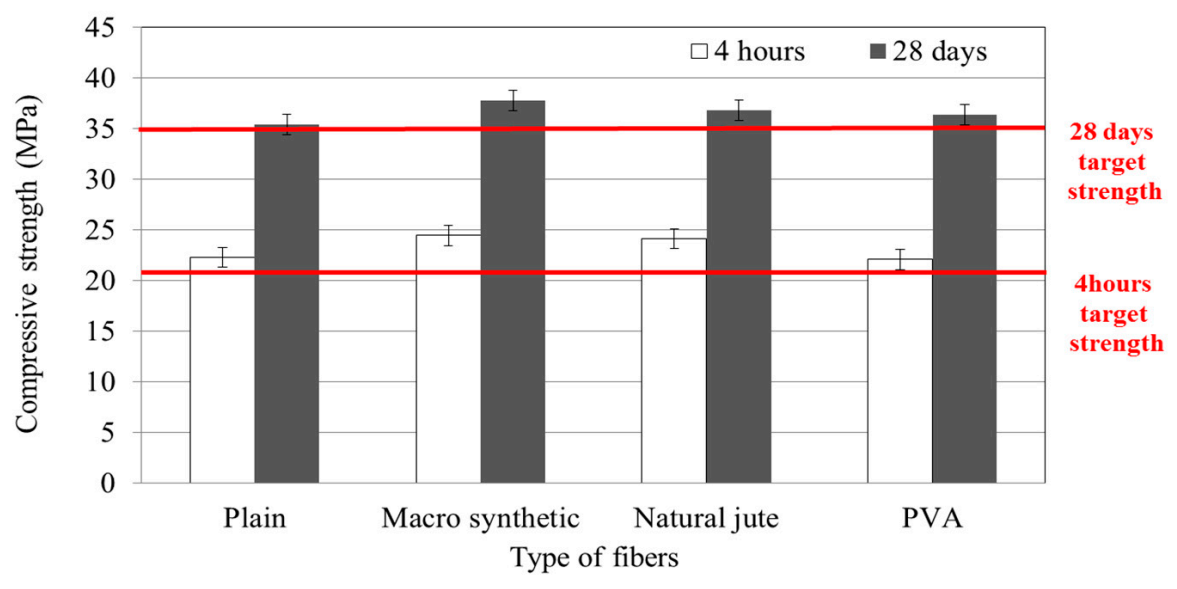

Figure 7. Compressive strength of RCLMFRRHCC.

\subsection{Flexural Strength}

The results of the flexural strength tests, according to the types of reinforcement fibers of RCLMFRRHCC for concrete pavement emergency repair, are shown in Figure 8. In this study, the flexural strength standard was based on the 4-h traffic open standard of 3.5 MPa and the 28-day curing standard of $4.5 \mathrm{MPa}$. The test results satisfied both standards. When latex and reinforcement fiber were added, they influenced the tensile force and flexural strength rather than the compressive strength [1-3,5]. Latex film has the effect of increasing the binding force between the materials when the concrete receives flexural or tensile load. Thus, it increases tensile force and flexural strength $[5,11,12]$. Furthermore, the reinforcement fibers increase the tensile force of the concrete itself and increase flexural strength by restraining crack generation [16-20]. In the flexural strength tests, the case using macro synthetic fibers showed the best performance, while natural Jute fiber and PVA fiber mixes exhibited nearly the same flexural strength. These results showed that the macro synthetic fiber, a structural fiber, improved the structural performance of the concrete [22,23]. Thus, the macro synthetic fiber appeared to serve a different purpose than PVA fiber and jute fiber, which are used to improve the durability by controlling crack formation in concrete. 


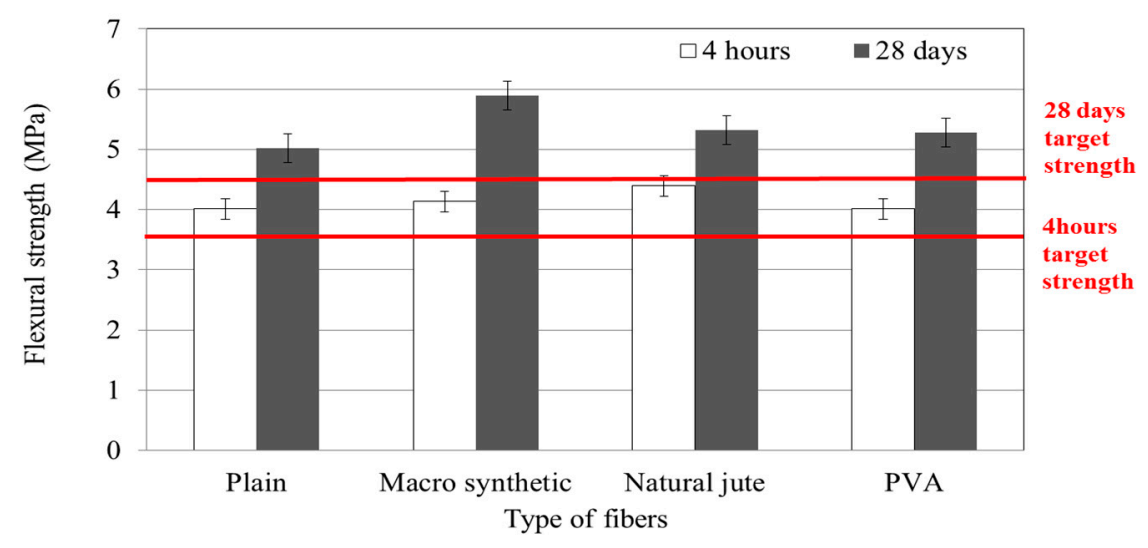

Figure 8. Flexural strength of RCLMFRRHCC.

\subsection{Splitting Tensile Strength}

In this study, the splitting tensile strength standard of RCLMFRRHCC for concrete pavement emergency repair was specified as $\geq 4.2 \mathrm{MPa}$ after 28 days of curing. Furthermore, this study aimed at a splitting tensile strength of $3.2 \mathrm{MPa}$ for $4 \mathrm{~h}$. The results of this study showed that the strength of 28 days of curing was satisfied in all mixtures. However, in the case of splitting tensile strength at the curing time of $4 \mathrm{~h}$, the plain mixture without reinforcing fibers showed a strength of approximately 3.1 MPa, which was slightly lower than the target splitting tensile strength (Figure 9). Furthermore, compared with the "plain" mix, the mixes with reinforcement fibers showed splitting tensile strength values of $\geq 3.2 \mathrm{MPa}$ and $4.5 \mathrm{MPa}$ at $4 \mathrm{~h}$ and 28 days, respectively. Thus, the reinforcement fiber increased the splitting tensile strength. RCLMFRRHCC for concrete pavement emergency repairs showed high hydration heat in the early stages of curing, improving the initial strength $[1-3,5,6]$. Thus, although cracks occurred within the concrete, the reinforcement fibers effectively prevented the generation and growth of cracks [16-23]. This effect was seen in the increased splitting tensile strength of RCLMFRRHCC. Furthermore, the addition of reinforcing fibers is more effective in increasing tensile strength than compressive strength [22,23]. Furthermore, the case using macro synthetic fibers showed better splitting tensile strength than the mixes with natural jute fibers and PVA fibers. This is because the macro synthetic fiber is a structural fiber, which is used to replace steel fiber and improves the structural performance of the concrete [22,23]. However, natural jute fibers and PVA fibers are crack-control fibers, which are used to improve durability rather than structural performance [16].

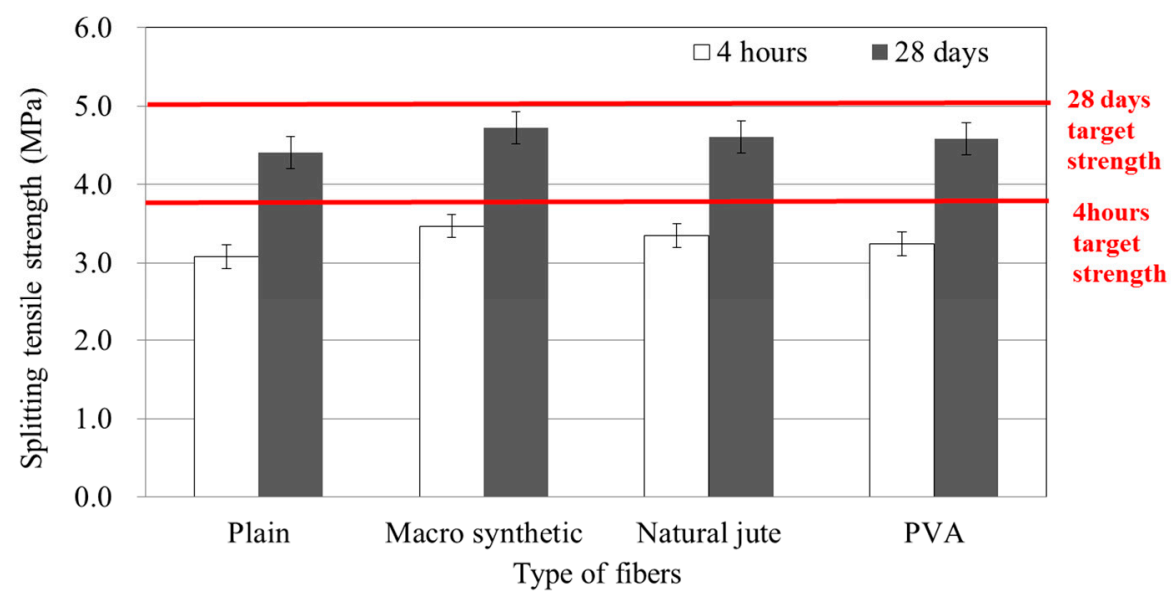

Figure 9. Splitting tensile strength of RCLMFRRHCC. 


\subsection{Chloride Ion Penetration}

Figure 10 shows the results of the chloride ion penetration tests for RCLMFRRHCC samples according to the type of reinforcement fiber. All samples satisfied the goal of chloride ion penetration of 2000 Coulombs after 28 days of curing. However, the target value of 4000 Coulombs or less at $4 \mathrm{~h}$ of curing were not achieved by the plain mixture without added fibers.

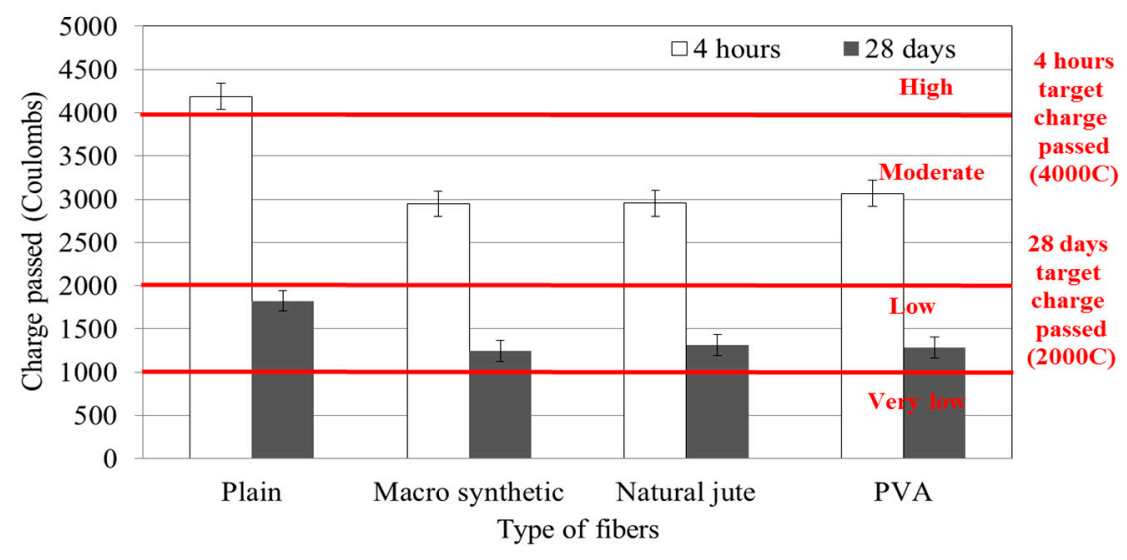

Figure 10. Chloride ion penetration test results.

Chloride ion penetration amount affects indirectly the concrete's water penetration properties [5,14,30]. The mixes with added reinforcement fibers showed decreased chloride ion penetration [10-12]. Generally, in cases of latex-modified concrete, the addition of latex fills air pores inside the concrete and forms a thick latex film layer, having the effect of reducing water penetration $[1-3,5,6]$. In this study, with latex addition (5\% of cement weight) and under pressure vibration compaction, lower chloride ion penetration amounts were achieved. When reinforcement fibers were added, there was a further reduction in the penetration amount $[5,14]$.

Particularly in the case of rapid-hardening cement concretes, cracks occur inside the cement due to high hydration heat in the early stages [1-3]. The addition of reinforcement fibers appeared to offset hydration heat-induced crack formation $[5,13]$. The mixes/test samples showed similar results in this regard. After curing for $4 \mathrm{~h}$, water penetration was fairly high in the mix with no fibers. However, all cases with added reinforcement fibers showed moderate water penetration properties. Since the reinforcing fibers inhibit the internal cracks due to the generation of hydration heat before sufficient strength is developed, the chlorine ion penetration amount decreases earlier than the mixture without the fibers. Therefore, it can be concluded that the addition of reinforcing fibers is effective in reducing the chloride ion penetration at the initial curing period in the repair concrete before the initial sufficient strength is developed. However, after curing for 28 days, all samples showed low water penetration.

\subsection{Abrasion Resistance}

Figure 11 shows the abrasion test results for RCLMFRRHCC for concrete pavement emergency repair according to reinforcement fiber type. Mixes using reinforcement fibers showed improved abrasion resistance. This was because the reinforcement fibers provided a bridging effect to hold the concrete particles [11,14]. There was no major difference in terms of reinforcement fiber type. Thus, abrasion resistance improved with the addition of reinforcement fibers by effectively tightening the internal structure. Furthermore, the increase in abrasion resistance with the addition of reinforcing fibers is influenced by the bonding properties of concrete and reinforcing fibers [11,14]. Notably, natural jute and PVA fibers are 'water-friendly fibers' and thus, they adhere strongly to the concrete matrix for enhanced abrasion resistance $[10,11,16]$. The macro synthetic fiber has a crimped surface shape, which markedly improves bonding with the concrete [22,23]. 


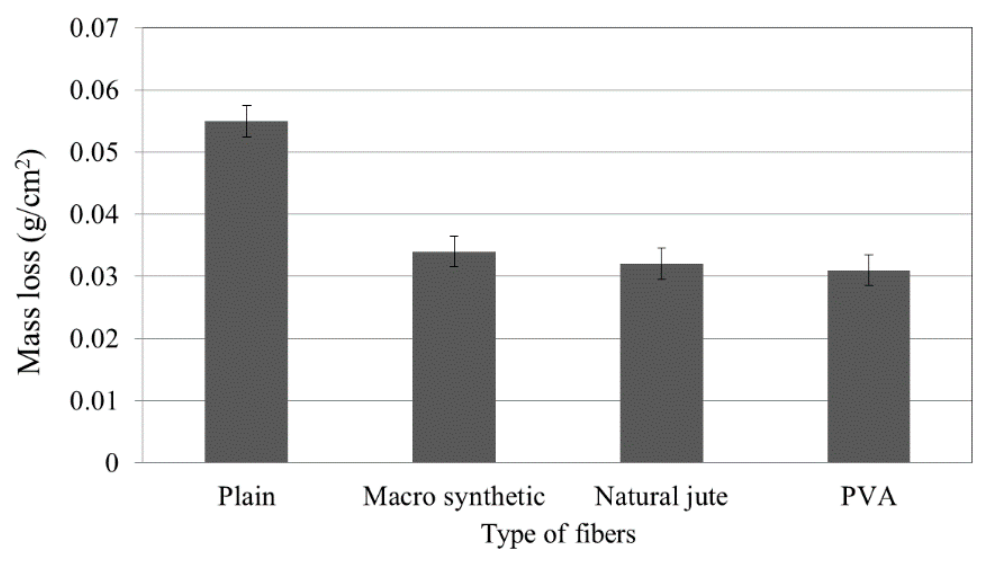

Figure 11. Abrasion test results.

\subsection{Impact Resistance}

RCLMFRRHCC impact test results for concrete pavement emergency repair, according to the type of reinforcement fibers, are shown in Figure 12. Mixes with added reinforcement fibers showed increased numbers of impacts before reaching destruction. In the case of the plain mix with no fiber, the number of impacts was approximately 200 times. Mixes containing reinforcement fibers showed approximately 400 impacts, which was about a two-fold impact improvement in resistance. The mixes using reinforcement fibers showed increased flexural characteristics and energy absorption ability, based on bridging effects and pull out, fiber de-bonding in addition to fiber fracture resistance under impact $[10,11]$. Furthermore, the impact resistance due to the addition of the reinforcing fibers is determined by the bonding characteristics of the reinforcing fibers [10,11]. In this study, bonding with concrete was excellent after applying hydrophilic fibers that achieved strong bonding to concrete and fibers with crimped type fibers. Therefore, the impact resistance was increased. According to the reinforcement fiber type, the number of impacts before destruction using the macro synthetic fiber was approximately 490 times and 410-415 times for added natural jute and PVA fiber mixes, respectively. Natural jute fibers and PVA fibers showed almost the same impact resistance, while the mix using macro synthetic fiber showed better impact resistance. This is because the macro synthetic fiber is a structural fiber with a larger fiber diameter and longer length compared with natural jute and PVA fibers. As the macro synthetic fiber is intended as a structural reinforcement fiber, it shows outstanding resistance against impact, which involves energy absorption ability and flexural characteristics [22,23].

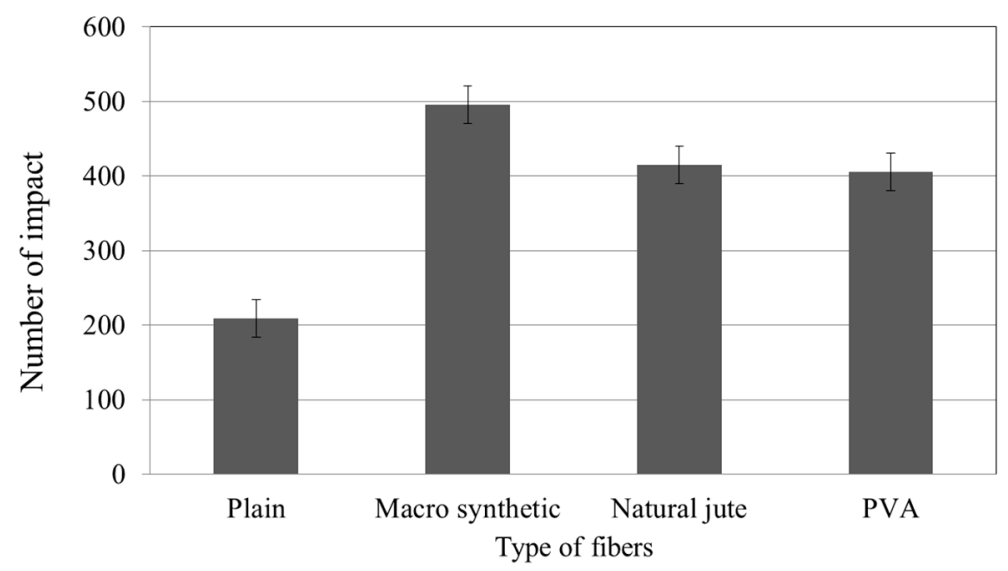

Figure 12. Impact test results. 


\subsection{Economical Comparison of Materials Used}

In this study, the use of latex was reduced to improve the strength development, roller compaction method and economic efficiency of the materials used with the latex addition of RCLMFRRHCC. The latex was reduced from $15 \%$ to $10 \%$ by weight of cement. To reduce the durability due to the decrease in the latex usage and to secure the applicable slump of the roller-compacting method, reinforcing fibers were applied. In this study, the cost of input materials was compared and analyzed. The costs of the materials used in this study are shown in Table 7. The cost of the material was provided by the manufacturer. At this time, coarse aggregate, fine aggregate and water were excluded because the same amount was applied. The comparative mix was compared with the addition of $15 \%$ of latex. Table 8 shows the comparison results. Figure 13 compares the economics of the cost of latex and reinforcing fibers for the same amount of rapid set cement. Excluding rapid-hardening cement, mixtures with 5\% latex and fiber reduces $60-63 \%$ of material costs compared with $15 \%$ latex. Therefore, it is possible to reduce the use of latex as well as to use a roller-compacting method by using reinforcing fibers.

Table 7. Costs of materials (provided by manufacturer).

\begin{tabular}{ccccc}
\hline \multicolumn{5}{c}{ Material Cost (won */kg) } \\
\hline Rapid Set Cement & Latex & Macro Synthetic Fiber & Natural Jute Fiber & PVA Fiber \\
\hline 700 & 1640 & 5000 & 4500 & 5000 \\
\hline
\end{tabular}

Table 8. Comparing the costs of the material mixtures for repairing pavement.

\begin{tabular}{|c|c|c|c|c|c|c|}
\hline Mix No. & $\begin{array}{l}\text { Rapid Set } \\
\text { Cement Unit: } \\
\text { Won (Usage) }\end{array}$ & $\begin{array}{c}\text { Latex Unit: } \\
\text { Won (Usage) }\end{array}$ & $\begin{array}{l}\text { Macro Synthetic } \\
\text { Fiber Unit: Won } \\
\text { (Usage) }\end{array}$ & $\begin{array}{l}\text { Natural Jute } \\
\text { Fiber Unit: } \\
\text { Won (Usage) }\end{array}$ & $\begin{array}{l}\text { PVA Fiber Unit: } \\
\text { Won (Usage) }\end{array}$ & $\begin{array}{l}\text { Total Unit: } \\
\text { Won }\end{array}$ \\
\hline Latex $(15 \%)$ & $280,000(400 \mathrm{~kg})$ & $98,400(60 \mathrm{~kg})$ & - & - & - & 378,400 \\
\hline Plain (latex: 5\%) & $280,000(400 \mathrm{~kg})$ & $32,800(20 \mathrm{~kg})$ & - & - & - & 312,800 \\
\hline Macro synthetic fiber & $280,000(400 \mathrm{~kg})$ & $32,800(20 \mathrm{~kg})$ & $4550(0.91 \mathrm{~kg})$ & - & - & 317,350 \\
\hline Natural jute fiber & $280,000(400 \mathrm{~kg})$ & $32,800(20 \mathrm{~kg})$ & - & $5670(1.26 \mathrm{~kg})$ & - & 318,470 \\
\hline PVA fiber & $280,000(400 \mathrm{~kg})$ & $32,800(20 \mathrm{~kg})$ & - & - & $6300(1.26 \mathrm{~kg})$ & 319,100 \\
\hline
\end{tabular}

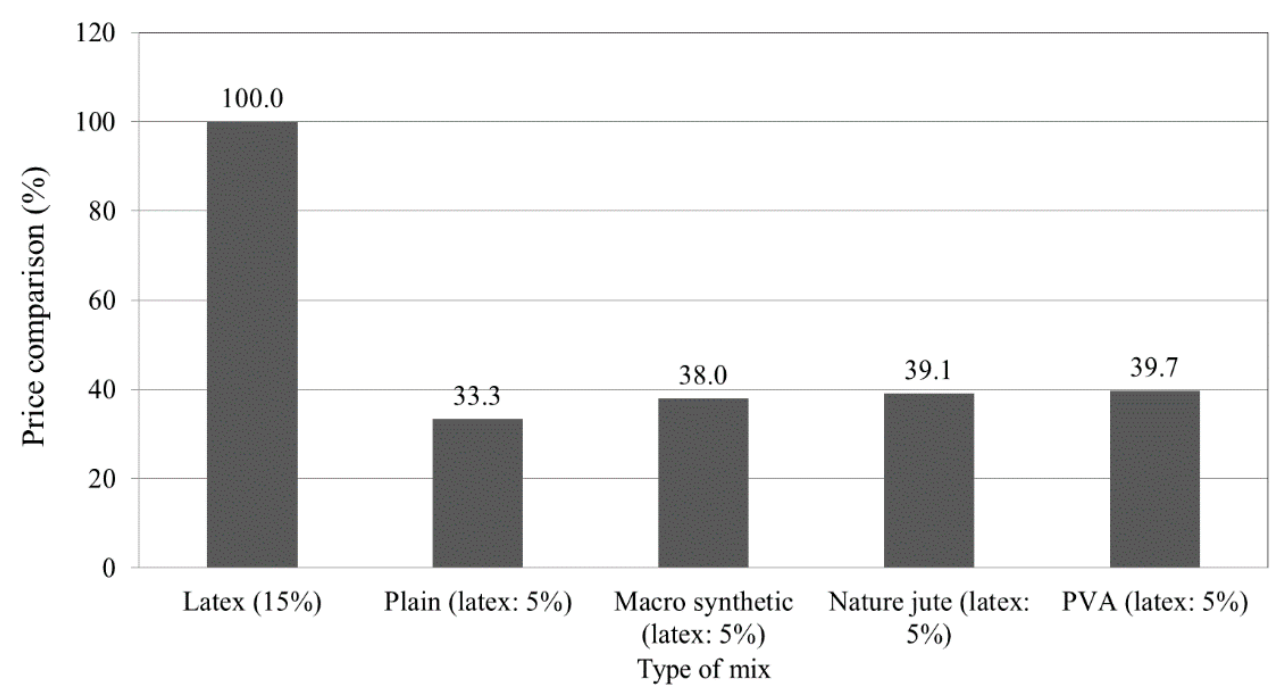

Figure 13. Comparing the cost reductions of a mixture of materials for repairing pavement.

\section{Conclusions}

This study evaluated the influence of reinforcement fibers on the performance of RCLMFRRHCC for concrete pavement emergency repairs. A summary of the test results is as follows: 
- As a result of the slump test, the slump of $40 \mathrm{~mm}$ or less for applying the roller compaction method could be satisfied by adding the fiber. Therefore, it is difficult to apply the roller compaction method without mixing the fiber.

- In compressive strength tests, all mixes showed results satisfying the traffic open standard curing at $4 \mathrm{~h}$ of $\geq 21 \mathrm{MPa}$ and curing for 28 days of $\geq 35 \mathrm{MPa}$. The mixes using reinforcement fibers showed outstanding compressive strength. The macro synthetic fiber, used as a structural fiber, showed better results than those of natural jute fibers and PVA fibers, which are non-structural fibers.

- In flexural strength tests, all mixes satisfied the strength condition of $\geq 3.5 \mathrm{MPa}$ after $4 \mathrm{~h}$ of curing and $\geq 4.5 \mathrm{MPa}$ after 28 days of curing. The macro synthetic fiber, a structural fiber, showed better results than using the natural jute fiber and PVA fiber (non-structural fibers).

- In the splitting tensile strength results, all mixes satisfied the target of 4.2 MPa after curing for 28 days. Regarding the influence of the fiber reinforcement materials, the macro synthetic fiber showed better results than using natural jute fibers or PVA fibers.

- From chloride ion penetration test results, mixes with reinforcement fibers showed a decreased chloride ion penetration. All mixes satisfied the target standard of $\leq 2000$ Coulombs after curing for 28 days. However, in the case of a curing period of $4 \mathrm{~h}$, the mix without reinforcing fibers showed a value of 4000 or more and showed high permeability. The mixture with the reinforcing fibers shows moderate permeability.

- The resistance of permeability was improved compared to that without fiber reinforcement.

- In abrasion test results, mixes with reinforcement fibers showed increased abrasion resistance. The influence of the reinforcement fiber type was not significant.

- In the impact test results, mixes with reinforcement fibers showed increased impact resistance. The mix using macro synthetic fibers showed better resistance against impact than mixes with natural jute fiber and PVA fiber.

- In this study, considering the strength, permeability and durability, the fiber that was most effective in improving the performance of RCLMFRRHCC was the macro synthetic fiber.

- Furthermore, as a result of this study, RCLMFRRHCC can be applied to emergency repair of concrete pavement, as it can improve the economic efficiency by reducing the amount of latex used in addition to satisfying the target performance and improving the durability of concrete pavement.

- Cost analysis of materials, excluding rapid-hardening cement, found that the mixtures with $5 \%$ latex and fiber reduce $60-63 \%$ of material costs compared with $15 \%$ latex. Therefore, it is possible to reduce the use of latex as well as to use a roller-compacting method by using reinforcing fibers.

Acknowledgments: This work was supported by the research grant of the Kongju National University in 2016.

Author Contributions: Seung-Kee Lee conceived and designed the experiments; Mong-Jin Jeon and Sang-Sun Cha performed the experiments; Chan-Gi Park analyzed the data and wrote the paper. All authors have read and approved the final manuscript.

Conflicts of Interest: The authors declare no conflict of interest.

\section{References}

1. Sprinkel, M. Latex-Modified Concrete Overlay Containing Type K Cement; FHWA/VTRC 05-R26; Virginia Transportation Research Council: Charlottesville, VA, USA, 2005.

2. Sprinkel, M. High Early Strength Latex Modified Concrete Overlay; Report VTRC 88-R12; Virginia Transportation Research Council: Charlottesville, VA, USA, 1998.

3. Sprinkel, M. Very-Early-Strength Latex-Modified Concrete Over-Lays; TAT99-TAR3; Virginia Transportation Research Council: Charlottesville, VA, USA, 1998.

4. Buch, N.; Van Dam, T.J.; Peterson, K.; Sutter, L. Evaluation of high-early strength PCC mixtures used in full depth repairs. Constr. Build. Mater. 2008, 22, 162-174. [CrossRef] 
5. Han, J.-W.; Jeon, J.-H.; Park, C.-G. Mechanical and Permeability Characteristics of Latex-Modified Pre-Packed Pavement Repair Concrete as a Function of the Rapid-Set Binder Content. Materials 2015, 8, 6728-6737. [CrossRef]

6. Won, J.P.; Kim, J.H.; Park, C.G.; Kang, J.W. Shrinkage cracking of styrene butadiene polymeric emulsion-modified concrete using rapid-hardening cement. J. Appl. Polym. Sci. 2009, 112, 2229-2234. [CrossRef]

7. Zuniga, J.R. Development of Rapid, Cement-Based Repair Materials for Transportation Structures. Master's Thesis, The University of Texas at Austin, Austin, TX, USA, 2013.

8. Bull, J.W.; Woodford, C.H. Design of precast concrete pavement units for rapid maintenance of runways. Comput. Struct. 1997, 64, 857-864. [CrossRef]

9. Ackroyd, R.F.; Bull, J.W. The design of precast concrete pavements on low bearing capacity subgrades. Comput. Geotech. 1985, 1, 279-291. [CrossRef]

10. Kim, D.H.; Park, C.G. Permeability, abrasion, and impact resistance of latex-modified fiber reinforced concrete for precast concrete pavement application. Prog. Rubber Plast. Recycl. Technol. 2013, 29, 239-254.

11. Oh, R.O.; Kim, D.H.; Park, C.G. Durability performance of latex modified nylon fiber reinforced concrete for precast concrete pavement applications. Indian J. Eng. Mater. Sci. 2014, 21, 49-56.

12. Won, J.P.; Kim, J.H.; Lee, S.W.; Park, C.G. Durability of Low-Heat, Ultra Rapid-Hardening, Latex Modified Polymer Concrete. Prog. Rubber Plast. Recycl. Technol. 2009, 25, 91-102.

13. Yun, K.K.; Choi, P. Causes and controls of cracking at bridge deck overlay with very-early strength latex-modified concrete. Constr. Build. Mater. 2014, 56, 53-62. [CrossRef]

14. Kim, D.H.; Park, C.G. Strength, permeability and durability of hybrid fiber-reinforced concrete containing styrene butadiene latex. J. Appl. Polym. Sci. 2013, 129, 1499-1505. [CrossRef]

15. Won, J.P.; Kim, J.M.; Lee, S.J.; Lee, S.W.; Park, S.K. Mix proportion of high-strength, roller-compacted, latex-modified rapid-set concrete for rapid road repair. Constr. Build. Mater. 2011, 25, 1796-1800. [CrossRef]

16. Bentur, A.; Mindess, S. Fiber Reinforced Cementitious Composites; Elsevier Applied Science: London, UK, 1992.

17. Chan, Y.W.; Chu, S.H. Effect of silicafume on steel fiber bond characteristics in reactive powder concrete. Cem. Concr. Res. 2004, 34, 1167-1172. [CrossRef]

18. Mobasher, B.; Li, C.Y. Effect of interfacial properties on the crack propagation in cementitious composites. Adv. Cem. Based Mater. 1996, 4, 93-105. [CrossRef]

19. Naaman, A.E.; Najm, H. Bond-slip mechanism of steel fibers in concrete. ACI Mater. J. 1991, 88, 135-145.

20. Shannag, M.J.; Brinker, R.; Hansen, W. Pullout behavior of steel fibers from cement-based composites. Cem. Concr. Res. 1997, 27, 925-936. [CrossRef]

21. Singha, S.; Shuklaa, A.; Brown, R. Pullout behavior of polypropylene fibers from cementitious matrix. Cem. Concr. Res. 2004, 34, 1919-1925. [CrossRef]

22. Won, J.P.; Lim, D.H.; Park, C.G.; Park, H.G. Bond behavior and flexural performance of structural synthetic fiber reinforced concrete. Mag. Concr. Res. 2003, 28, 401-410.

23. Won, J.P.; Park, C.G.; Lee, S.W.; Jang, C.I.; Kim, H.Y. Performance of synthetic macrofibers in reinforced concrete for tunnel linings. Mag. Concr. Res. 2009, 61, 165-172. [CrossRef]

24. ACI. 325.10R-95, State-of-the-Art Report on Roller Compacted Concrete Pavements; Technical Report; American Concrete Institute: Farmington Hills, MI, USA, 1995.

25. Jeff, L.; Sachindra, D.; Jeffery, R.; Armen, N.A. Mechanical properties of roller-compacted concrete with macro-fibers. Constr. Build. Mater. 2017, 135, 440-446.

26. Krishna Rao, S.; Sravana, P.; Chandrasekhar Rao, T. Abrasion resistance and mechanical properties of Roller Compacted Concrete with GGBS. Constr. Build. Mater. 2016, 114, 925-933.

27. John, N.K.; Yougui, L. Flexural strengths and fiber efficiency of steel-fiber-reinforced, roller-compacted, polymer modified concrete. Constr. Build. Mater. 2015, 93, 498-505.

28. AASHTO. Standard Specification of Rigid Pavement; American Association of State Highway and Transportation Officials: Washington, DC, USA, 1998.

29. Korea Expressway Corporation. Construction Material Quality and Standard for Highway Construction; Korea Expressway Corporation: Seongnam, Korea, 2005.

30. ASTM. ASTM C1202. Standard Test Method for Electrical Indication of Concrete's Ability to Resist Chloride Ion Penetration; American Society for Testing and Materials: Philadelphia, PA, USA, 2012. 
31. Ministry of Land, Transport and Maritime Affairs. Cement Pavement Guidelines; Ministry of Land, Transport and Maritime Affairs: Seoul, Korea, 2009.

32. ASTM. ASTM C143, Standard Test Method for Slump of Hydraulic-Cement Concrete; American Society for Testing and Materials: Philadelphia, PA, USA, 2015.

33. ASTM. ASTM C39. Standard Test Method for Compressive Strength of Cylindrical Concrete Specimens; American Society for Testing and Materials: Philadelphia, PA, USA, 2015.

34. ASTM. ASTM C496/C496M. Standard Test Method for Splitting Tensile Strength of Cylindrical Concrete Specimens; American Society for Testing and Materials: Philadelphia, PA, USA, 2011.

35. ASTM. ASTM C 78/C78M. Standard Test Method for Flexural Strength of Concrete (Using Simple Beam with Third-Point Loading); American Society for Testing and Materials: Philadelphia, PA, USA, 2015.

36. ASTM. ASTM C944. Standard Test Method for Abrasion Resistance of Concrete or Mortar Surfaces by the Rotating-Cutter Method; American Society for Testing and Materials: Philadelphia, PA, USA, 2012.

37. ACI Committee. 544.2R-89: Measurement of Properties of Fiber Reinforced concrete. ACI Mater. J. 1998, 85, 583-593.

(C) 2017 by the authors. Licensee MDPI, Basel, Switzerland. This article is an open access article distributed under the terms and conditions of the Creative Commons Attribution (CC BY) license (http://creativecommons.org/licenses/by/4.0/). 